\title{
Synthesis and Mass Spectrometry Analysis of Mimosine-Containing Peptides
}

\author{
Remigiusz Bąchor ${ }^{1}$ (I) - Enrico Randaccio ${ }^{2}$. Joanna I. Lachowicz ${ }^{2}$. Piotr Stefanowicz ${ }^{1}$. Valeria M. Nurchi ${ }^{2}$. \\ Zbigniew Szewczuk $^{1}$
}

Accepted: 19 June 2020 / Published online: 29 June 2020

(c) The Author(s) 2020

\begin{abstract}
Non-proteinogenic amino acids are widely explored group of compounds due to their chemical properties and great potential of application in the combinatorial chemistry, medicinal investigation etc. Therefore the synthetic methods of their incorporation to the peptide chain are required. L-Mimosine, $(S)$ - $\alpha$-amino- $\beta$-(3-hydoxy-4-oxo-1,4-dihydropyridin-1-yl)-propanoic acid), is a plant amino acid, known to induce apoptosis in human pancreatic cancer xenografts. Here we present our investigations on the synthesis of mimosine-containing peptide and their ESI-MS/MS analysis. We successfully applied Fmoc-protected mimosine a with a free hydroxy ketone group for efficient peptide synthesis in the presence of HATU as a coupling reagent without the formation of side products. Additionally the tandem mass spectrometry analysis revealed the characteristic loss of the heterocyclic ring from mimosine residue side chain. The described method allows insertion of mimosine residue at any endo-position within a peptide sequence. The obtained results may be useful in the synthesis and mass spectrometry analysis of various mimosine-containing peptides.
\end{abstract}

Keywords Mimosine $\cdot$ Peptide synthesis $\cdot$ ESI-MS/MS

\section{Abbreviations \\ Mim L-Mimosine \\ UAa Unnatural amino acids}

\section{Introduction}

Unnatural amino acids (UAa) are a large group of natural and chemically synthesized compounds commonly applied in the peptide synthesis. Due to their wide structural diversity and functional versatility, UAa are potent chemicals in the investigations of new pharmacologically active peptidic and non-peptidic compounds. Their application to peptide

Electronic supplementary material The online version of this article (https://doi.org/10.1007/s10989-020-10092-w) contains supplementary material, which is available to authorized users.

Remigiusz Bąchor

remigiusz.bachor@chem.uni.wroc.pl

1 Faculty of Chemistry, University of Wroclaw, F. Joliot-Curie 14, 50-383 Wrocław, Poland

2 Department of Chemical and Geological Science, University of Cagliari, Cittadella Universitaria, 09042 Monserrato-Cagliari, Italy combinatorial libraries may significantly expand the area of drug discovery benefited from novel, short-chain peptide ligand mimetics (peptidomimetics) with both enhanced biological activity and proteolytic resistance (Poreba et al. 2014). Additionally, their application as molecular probes may help in better understanding of the biological systems functions (Kasperkiewicz et al. 2014). In these areas, the unnatural amino acids are often incorporated via solid phase synthesis according to Fmoc strategy. Due to the chemical structure of wide group of unnatural amino acids containing different side chain functionalities, the application of nonstandard protecting groups and deportation may be require for the solid phase synthesis. Additionally the methods of peptide synthesis using amino acid residues without side protection are under investigations because it makes the synthesis simple and cost-efficient.

L-Mimosine (Mim, (S)- $\alpha$-amino- $\beta$-(3-hydoxy-4-oxo-1,4dihydropyridin-1-yl)-propanoic acid), is a naturally occurring non-proteinogenic amino acid found in several tropical and subtropical plants where the alanine side chain is bounded to the nitrogen atom of a dihydropyridin ring. The simple and low cost methods of preparative scale extraction from the natural sources and purification of Mim have also been developed (Nokihara et al. 2012; Tawata 1994). It 
was found that mimosine is responsible for the allelopathy of the plants (Nokihara et al. 2012; Xuan et al. 2006). The therapeutic roles of mimosine including antiproliferative and antifibrotic (Ju et al. 1998), antitumor (DeWys and Hall 1973), antiviral (Dai et al. 1994; Andrus et al. 1998) and in addition, the anti-tyrosinase activity has been studied, and are promissing in drug development. The tyrosinase inhibitory activities of Mim are also of interest in the cosmetic field for whitening. However, the confined supply of Mim and limited knowledge of its properties have restricted its use and potential for future industrial applications. Due to the similarity of the mimosine side chain to the kojic acid, Mim is a tyrosine analog and could potentially be used for designing more potent tyrosinase inhibitors (Lachowicz et al. 2015; Andrus et al. 1998) and form the complexes with metal ions like iron (III) or aluminium (III) (Lachowicz et al. 2015, 2016; Toso et al. 2013, 2014; Nurchi et al. 2014).

Many attempts were made to obtain peptides conjugated with Mim. The Mim-containing peptides were investigated towards their inhibitory activity relative to melanogenesis and cyclooxygenase (Nguyen and Tawata 2015), neuraminidase (Upadhyay et al. 2011) and tyrosinase (Nokihara et al. 2012). Fmoc-Mim without any protection of hydroxy ketone group in its side chain was coupled to peptides on solid support (Nguyen and Tawata 2015; Upadhyay et al. 2011). Nokihara and co-workers (Nokihara et al. 2012) also applied the Fmoc-Mim(tBu)-OH derivative for synthesis of model dipeptide on a solid phase. However, to date, all of the synthesized peptides contain Mim residue on N-terminus only, since the last coupling step during synthesis on solid support was introduction of Fmoc-Mim, following by deprotection of the Fmoc group and cleavage of a conjugated peptide from a solid support. However it be expected that insertion of the Mim residue in C-terminal or any endo-positions within a peptide sequence may open a new possibilities in synthesis of various Mim-containing peptides.

Herein we present solid phase synthesis of peptides containing Mim residues in different positions in the peptide chain.

\section{Materials and Methods}

\section{Reagents}

All solvents and reagents were used as supplied. Fmoc amino acid derivatives were purchased from Novabiochem. L-Mimosine was obtained from Sigma Aldrich.

$O$-(7-azabenzotriazol-1-yl)- $N, N, N^{\prime}, N^{\prime}$-tetramethyluronium hexafluorophosphonate (HATU), the MBHA-Rink amide resin $(0.69 \mathrm{mmol} / \mathrm{g})$, Fmoc-Gly-Wang resin $(0.73 \mathrm{mmol} / \mathrm{g})$ and trifluoroacetic acid (TFA) were obtained from IrisBiotech. Solvents for peptide synthesis $(N, N$-dimethylformamide (DMF), dichloromethane (DCM), and ( $N$-ethyldiisopropylamine (DIEA)) were obtained from Sigma Aldrich.

\section{Fmoc-Mimosine Synthesis}

The synthesis of Fmoc-Mim derivative was performed using the method described by Upadhyay and co-workers (Upadhyay et al. 2011). Briefly, mimosine (200 mg) and sodium carbonate $\left(\mathrm{Na}_{2} \mathrm{CO}_{3}\right)(220 \mathrm{mg})$ were dissolved in distilled water $(3 \mathrm{ml})$. Fmoc-Osu $(500 \mathrm{mg})$ dissolved in $3,6 \mathrm{ml}$ of 1,4-dioxane was added dropwise to the solution and stirred for $20 \mathrm{~h}$ at room temperature. Next, $12 \mathrm{ml}$ of $\mathrm{Na}_{2} \mathrm{CO}_{3}(0.1$ M) was added. The mixture was stirred for $7 \mathrm{~h}$ at $26^{\circ} \mathrm{C}$ and was then filtered and washed with $20 \mathrm{ml}$ of ethyl acetate to remove excess Fmoc-Osu and by-products. The water fraction was kept in an ice bath and adjusted to $\mathrm{pH} 4.0$ using $6 \mathrm{~N} \mathrm{HCl}$ and incubated overnight at $4{ }^{\circ} \mathrm{C}$. The resulting precipitate was filtered, washed with distilled water, and dried under reduced pressure to give Fmoc-mimosine. The obtained product was analyzed by ESI-MS.

\section{Peptide Synthesis}

The synthesis of model peptides on the MBHA-Rink (peptides 1-3, Table 1), Fmoc-Gly-Wang resin (peptide 4, Table 1) and 2-chlorotrityl chloride resin was performed manually in

Table 1 The sequences of model Mim-containing peptides and the results of HPLC and ESI-MS analysis

\begin{tabular}{lllll}
\hline Peptide number & Peptide sequence & $\begin{array}{l}\text { Retention time } \\
(\mathrm{min})\end{array}$ & $\begin{array}{l}{[\mathrm{M}+\mathrm{H}]^{+} \text {found }} \\
\mathrm{m} / z^{a}\end{array}$ & $\begin{array}{l}{[\mathrm{M}+\mathrm{H}]^{+} \text {calculated for }} \\
\text { formula (monoisotopic) } \\
m / z^{a}\end{array}$ \\
\hline 1 & & 6.5 & 561.264 & 561.267 \\
2 & H-Mim-Val-Tyr-Thr-NH & 577.225 \\
3 & H-Asp-Mim-Tyr-Thr-NH & 577.227 & 513.230 \\
4 & H-Asp-Val-Mim-Thr-NH & 513.231 & 492.184 \\
5 & H-Mim-Gly-Mim-Gly-NH & 5.6 & 647.242 \\
6 & H-Mim-Gly-Pro-Gly-Mim-Gly-OH & 4.9 & 692.189 & 884.317 \\
\hline
\end{tabular}

${ }^{\mathrm{a}} \mathrm{m} / \mathrm{z}$, values are presented for the monoisotopic ions 
polypropylene syringe reactors (Intavis AG) equipped with polyethylene filters, according to a standard Fmoc (9-fluorenylmethoxycarbonyl) solid phase synthesis procedure (Nguyen and Tawata 2015). In the case of 2-chlorotrithyl chloride resin the synthesis was performed according to the method described by Nokihara and co-workers (Nokihara et al. 2012).

\section{Purification}

All products were purified using the analytical HPLC Thermo Separation system with UV detection $(210 \mathrm{~nm})$ with a YMCPack RP C18 column $(4.6 \times 250 \mathrm{~mm}, 5 \mu \mathrm{m})$, with a gradient elution of $0-40 \% B$ in $A(A=0.1 \%$ TFA in water; $B=0.1 \%$ TFA in acetonitrile/ $\mathrm{H}_{2} \mathrm{O}, 4: 1$ ) over $30 \mathrm{~min}$ (flow rate $1 \mathrm{ml} /$ $\min$ ). The main fraction, corresponding to the peptide, was collected and lyophilized.

\section{Mass Spectrometry}

All ESI-MS experiments were performed on a micrOTOFQ mass spectrometer (Bruker Daltonics, Bremen, Germany) and on an FTICR (Fourier Transform Ion Cyclotron Resonance) Apex-Qe Ultra 7T mass spectrometer (Bruker Daltonics, Bremen, Germany) equipped with standard ESI source. The instruments were operated in the positive-ion mode and calibrated with the Tunemix ${ }^{\mathrm{TM}}$ mixture (Agilent Technologies, Palo Alto, CA, USA). The mass accuracy was better than 5 ppm. Analyte solutions $(70 \mu \mathrm{l})$ were introduced at a flow rate of $3 \mu \mathrm{L} / \mathrm{min}$. The instruments parameters were as follows: for micrOTOF-Q MS: scan range: 50-1600 $\mathrm{m} / \mathrm{z}$; drying gas: nitrogen; flow rate: $4.0 \mathrm{~L} / \mathrm{min}$, temperature: $200^{\circ} \mathrm{C}$; potential between the spray needle and the orifice: $4.2 \mathrm{kV}$; for FTICR MS: scan range: $100-1600 \mathrm{~m} / z$; drying gas: nitrogen; flow rate: $1.5 \mathrm{~L} / \mathrm{min}$; temperature: $200{ }^{\circ} \mathrm{C}$; potential between the spray needle and the orifice: $4.2 \mathrm{kV}$.

\section{CID}

The singly charged $\left(\mathrm{M}+\mathrm{H}^{+}\right)$precursor ions were selected on the quadrupole and subsequently fragmented in the hexapole collision cell. Argon was used as a collision gas. The obtained fragments were registered as an MS/MS (tandem mass spectrometry) spectrum. The collision energy (10-30 V) was optimized for the best fragmentation. For MS spectra analysis, a Bruker Compass DataAnalysis 4.0 software was used.

\section{Results and Discussion}

The main goal of this work was to investigate the possibility of mimosine application in the efficient synthesis of peptide on solid support without side chain protection of hydroxy ketone group. In the case of commercially available amino acid residues the side chain functionalities are blocked to limit the possibility of side products formation. Therefore to protect the hydroxy ketone group we decided to use similar procedure as proposed previously by us for kojic acid to obtain the benzyl ether derivative (Upadhyay et al. 2011). As can be expected, the applied reaction causes benzylation of amino group however, the conversion of Z-Mim(OBzl)-OH after several steps is possible resulting in the formation of fully protected amino acid derivative which may be apply in the peptide synthesis. We found that the reaction conditions used for the benzyl ether formation caused decomposition of mimosine, thus this procedure is not practical for preparation of side chain protected Mim residue. Based on the data reported by Nokihara et al. (2012), different side chain protecting groups of hydroxy ketone group of mimosine present low stability. It was also mentioned by Nokihara and co-workers (Nokihara et al. 2012) that Fmoc-Mim-OH without side chain protection can be successfully apply for solid-phase peptide synthesis, while other protecting groups are not suitable for either temporary or permanent protection. Up to now the presented data described only the synthesis of peptides containing N-terminal Mim (Upadhyay et al. 2011; Nguyen and Tawata 2015; Nokihara et al. 2012). Therefore we decided to omit the hydroxy ketone group protection and apply Fmoc-Mim-OH derivative into the peptide synthesis. Due to the low reactivity of Fmoc-protected Mim in the coupling reaction (Nokihara et al. 2012), which may affect the reaction efficiency, we decided to apply two different coupling reagents, PyBOP and HATU, to analyze the effectiveness. The efficiency of coupling was analyzed by attaching the Mim residue to the glycine directly bounded to the resin in the presence of amine (DIPEA) and coupling reagent under room temperature $\left(24^{\circ} \mathrm{C}\right)$. The reaction was carried out within $2 \mathrm{~h}$ and then was controlled by Kaiser test (Kaiser et al. 1970). We found that even after triple coupling in th presence of PyBOP, the resin beads remain still blue. Therefore we applied HATU as more reactive coupling reagent in the peptide synthesis, as judged by the Kaiser test after first two hours of coupling reaction using three fold excess of Fmoc-Mim-OH. Previously Nokihara et al. mentioned that the coupling efficiency of Fmoc-Mim does not require an excess of Fmoc-Mim as acyl component and that the triple coupling of a three-fold excess gave an optimal yield (Nokihara et al. 2012). Therefore we synthesized different model peptides containing Mim in different positions (Table 1) using HATU as coupling reagent. Previous papers described application of Fmoc-Mim-OH without side chain hydroxy ketone group protection for synthesis of peptides containing mimosine residue on the $\mathrm{N}$-terminus only (Nguyen and Tawata 2015; Upadhyay et al. 2011), although the possibility of coupling of Fmoc-Mim-OH directly to the 2-chlorotrityl chloride resin was also presented (Nokihara et al. 2012), however without further modification. In this 
work a series of model peptides containing mimosine in different positions of peptide chain were successfully synthesized on solid support using Fmoc-Mim (Table 1). In the case of peptides 1-3 (peptide 1-3, Table 1) the DVYT sequence described previously by us as immunosuppressive fragment of HLA-DQ molecule (Szewczuk et al. 1996) was selected as a model due to the presence various side chain functionalities. We also synthesized the peptides containing two and three Mim residues and other amino acid residues without side chain functional groups (peptide 4, Table 1). Such models allow a wider analysis of possibility of FmocMim-OH application in the solid phase peptide synthesis. The synthesized peptides were cleaved from the resin using TFA/water/TIS (95/2.5/2.5 v/v) mixture which was also described as the most appropriate for Mim-containing peptides (Nokihara et al. 2012).

The collected HPLC fractions were then analyzed by ESI-MS and MS/MS techniques. On the ESI-MS spectra of all crude peptides 1-3 (Table 1) the most intensive signal corresponds to the protonated form $[\mathrm{M}+\mathrm{H}]^{+}$of the analyze peptide (Supplementary data, Figs. 1-3 S). The signals corresponding to the product where Mim was degradated to alanine have not been identified. Additionally signals shifted by $24 \mathrm{Da}$, reported by Nokihara and co-workers (Nokihara et al. 2012) have not been obtained. On the ESI-MS spectrum of peptide 5 (Table 1) the signal at $\mathrm{m} / \mathrm{z} 536.213$, corresponding to the peptide ion formed after Mim degradation to dehydroalanine was observed (Supplementary data, Fig. 5S). The ESI-MS spectrum of peptide 6 (Supplementary data, Fig. 6S) presents both signals corresponding to the singly and doubly $[\mathrm{M}+2 \mathrm{H}]^{2+}$ protonated peptide however, additional signals related to the mimosine degradation have not been identified. The obtained results suggest that the cleavage of Mim residue is not so common in the ESI-MS analysis of the mimosine-containing peptides. The fragmentation pathways of the synthesized peptides (Table 1) were analyzed by collision induced dissociation for singly charged ions $[\mathrm{M}+\mathrm{H}]^{+}$. The obtained spectra are presented in the Fig. 1. The details of the fragmentation pathways of peptides 1-3 are presented in supplementary materials (Figs. 7, 8 and $9 \mathrm{~S}$ ).

In the case of peptides 1-3 (Table 1) the obtained ESIMS/MS spectra present several signals corresponding mainly to the $\mathrm{N}$-terminal ion series and to the neutral losses of water or ammonia (Fig. 1a-c), resulting from the presence of side chain functional groups and the $\mathrm{C}$-terminal amide. In the case of all model peptides the signal corresponding to $b$ and $a$ ion series are present however, are characterized by small intensity. On the ESI-MS/MS spectrum of peptide 3 also the y type ion is present. For all analyzed peptides (1-3), the characteristic loss of $111 \mathrm{Da}$, in the form of $\mathrm{C}_{5} \mathrm{H}_{5} \mathrm{NO}_{2}$ group, corresponding to the heterocyclic ring of side chain of mimosine was observed. Such elimination

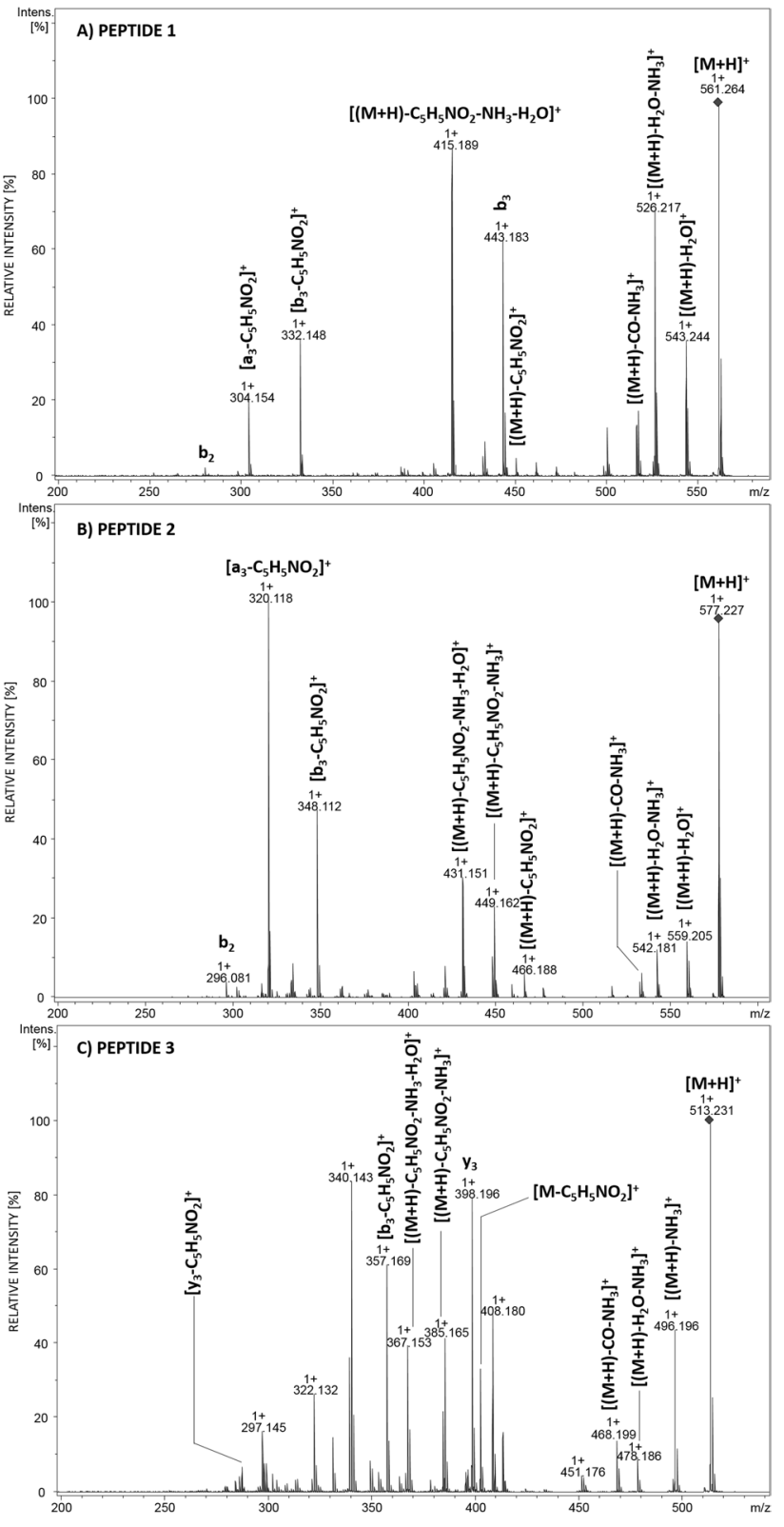

Fig. 1 ESI-MS/MS spectra of a peptide 1, parent ion $\mathrm{m} / z$ 561.264, collision energy 15 V. b Peptide 2, parent ion $\mathrm{m} / \mathrm{z}$ 577.227, collision energy $15 \mathrm{~V}$; c peptide 3, parent ion $\mathrm{m} / \mathrm{z}, 513.231$, collision energy 15 $\mathrm{V}$

occurs not only from the parent ion but also from other fragment ions corresponding to the $\mathrm{b}$ and a series and results in the formation of dehydroalanine derivative. Due to the presence of several signals on the obtained MS/MS spectra, corresponding to the neutral losses of small molecules which can make the interpretation of the fragmentation difficult, we decided to analyze other Mim-containing peptide (Table 1, peptides 4-6), to avoid the presence of signals which make the spectrum interpretation difficult. The obtained ESI-MS/ MS spectra pare presented in the Fig. 2. The details of the 
fragmentation pathways of peptides 4-6 are presented in supplementary materials (Figs. 10, 11 and $12 \mathrm{~S}$ ).

The ESI-MS/MS spectra of peptides 4-6 present mostly signals corresponding to the neutral loss of mimosine side chain (Fig. 2a-c). The performed ESI-MS/MS analysis of peptide 5 (Fig. 2b) containing two Mim residues revealed, that there is a characteristic dissociation of the heterocyclic ring in the side chain of mimosine residue which is confirmed by the signal at $m / z 438.2$ (Fig. 2b). The performed analysis, even at higher fragmentation energy, did not reveal any other signals corresponding to the fragment
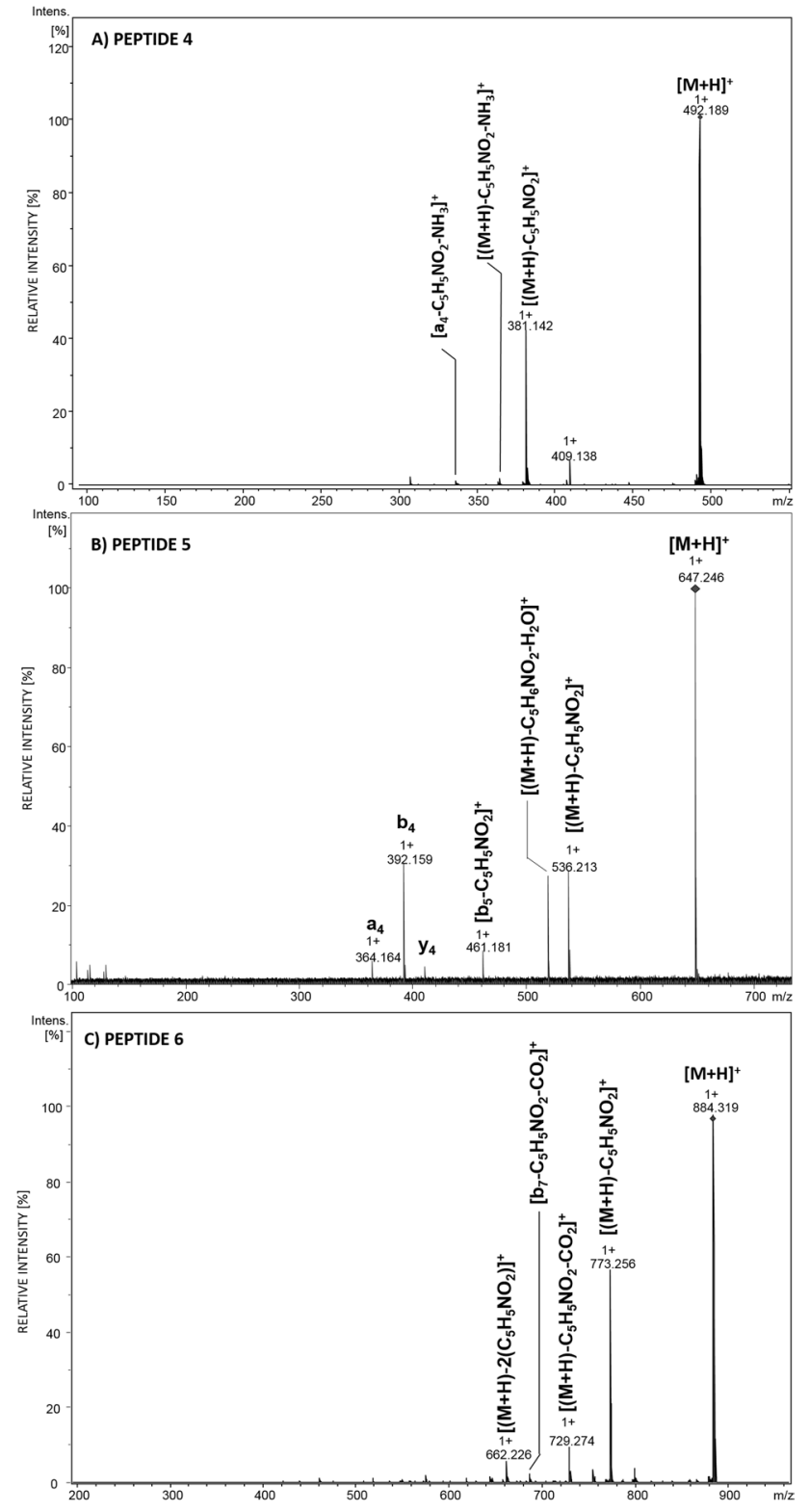

Fig. 2 ESI-MS/MS spectra of a peptide 4, parent ion $\mathrm{m} / \mathrm{z}$ 492.189, collision energy $25 \mathrm{~V}$. b Peptide 5, parent ion $\mathrm{m} / \mathrm{z}$ 647.246, collision energy $20 \mathrm{~V}$; c peptide 6, parent ion $\mathrm{m} / \mathrm{z} 884.319$, collision energy 25 $\mathrm{V}$ ions of model peptide. In conclusion, the performed ESIMS/MS analysis revealed that the neutral loss of $\mathrm{C}_{5} \mathrm{H}_{5} \mathrm{NO}_{2}$ group (111 Da), corresponding to the heterocyclic ring of side chain of mimosine is characteristic for the mimosine-containing peptides and may be useful in their quick identyfication. Such neutral loss (111 Da) may be useful in the analysis of mimosine-containing peptides by mass spectrometry using neutral loss scan. According to our knowledge such analysis has never been described before.

We also performed the ESI-MS experiment of model peptide with the peptides 4-6 (Table 1) containing two and three Mim residues in the chain with the addition of iron(III) chloride. Due to the similarity of Mim to the kojic acid, the formation of iron(III) complexes with Mim-containing peptide may be possible. After addition of the iron(III) ions the characteristic color of solution was observed however the intensity of the signal corresponding to the complex was very small and the identification of the obtained products on the obtained mass spectra both in the positive and negative ion mode was impossible. The iron complexes formed in solution, due to the week coordinated cation may dissociate under applied ESI conditions.

\section{Conclusions}

The series of model mimosine-containing peptides were synthesized efficiently on solid support using HATU as a coupling reagent Fmoc-Mim. Using the proposed condition protection of the mimosine side chain protection is not necessary. The obtained products were analyzed by tandem mass spectrometry which revealed a characteristic dissociation of heterocyclic ring from the side chain of mimosine residue which may be useful in the analysis of Mim-containing peptides by mass spectrometry. The presented procedure opens new possibility of synthesis of peptides containing mimosine residue at any terminal or endo-position within a peptide sequence.

Acknowledgements This work was supported by a Grant No. UMO2015/17/D/ST5/01329 from the National Science Centre, Poland.

\section{Compliance with Ethical Standards}

Conflict of interest The authors declare that they have no conflict of interest.

Research Involving Human and Animal Rights This article does not contain any studies with human participants or animals performed by any of the authors.

Open Access This article is licensed under a Creative Commons Attribution 4.0 International License, which permits use, sharing, 
adaptation, distribution and reproduction in any medium or format, as long as you give appropriate credit to the original author(s) and the source, provide a link to the Creative Commons licence, and indicate if changes were made. The images or other third party material in this article are included in the article's Creative Commons licence, unless indicated otherwise in a credit line to the material. If material is not included in the article's Creative Commons licence and your intended use is not permitted by statutory regulation or exceeds the permitted use, you will need to obtain permission directly from the copyright holder. To view a copy of this licence, visit http://creativecommons. org/licenses/by/4.0/.

\section{References}

Andrus L, Szabo P, Grady RW, Hanauske A-R, Huima-Byron T, Slowinska B, Zagulska S, Hanauske-Abel HM (1998) Antiretroviral effects of deoxyhypusyl hydroxylase inhibitors: a hypusine-dependent host cell mechanism for replication of human immunodeficiency virus type 1 (HIV-1). Biochem Pharmacol 55(11):1807-1818

Dai Y, Gold B, Vishwanatha JK, Rhode SL (1994) Mimosine inhibits viral DNA synthesis through ribonucleotide reductase. Virology 205(1):210-216

DeWys WD, Hall TC (1973) Anti-tumor effect of the amino acid mimosine. Eur J Cancer 9(4):281-283

Ju H, Hao J, Zhao S, Dixon IM (1998) Antiproliferative and antifibrotic effects of mimosine on adult cardiac fibroblasts. BBA-Mol Cell Res 1448(1):51-60

Kaiser E, Colescott R, Bossinger C, Cook P (1970) Color test for detection of free terminal amino groups in the solid-phase synthesis of peptides. Anal Biochem 34(2):595-598

Kasperkiewicz P, Poreba M, Snipas SJ, Parker H, Winterbourn CC, Salvesen GS, Drag M (2014) Design of ultrasensitive probes for human neutrophil elastase through hybrid combinatorial substrate library profiling. Proc Natl Acad Sci 111(7):2518-2523

Lachowicz JI, Nurchi VM, Crisponi G, Pelaez MdGJ, Rescigno A, Stefanowicz P, Cal M, Szewczuk Z (2015) Metal coordination and tyrosinase inhibition studies with Kojic- $\beta$ Ala-Kojic. J InorgBiochem 151:36-43

Lachowicz J, Nurchi V, Crisponi G, Jaraquemada-Pelaez M, Arca M, Pintus A, Santos M, Quintanova C, Gano L, Szewczuk Z (2016) Hydroxypyridinones with enhanced iron chelating properties. Synthesis, characterization and in vivo tests of 5-hydroxy-2-(hydroxymethyl) pyridine-4 (1 H)-one. Dalton Trans 45(15):6517-6528
Nguyen BCQ, Tawata S (2015) Mimosine dipeptide enantiomsers: improved inhibitors against melanogenesis and cyclooxygenase. Molecules 20(8):14334-14347

Nokihara K, Hirata A, Sogon T, Ohyama T (2012) Preparative scale isolation, purification and derivatization of mimosine, a non-proteinogenic amino acid. Amino Acids 43(1):475-482

Nurchi VM, Crisponi G, Arca M, Crespo-Alonso M, Lachowicz JI, Zoroddu MA, Peana M, Pichiri G, Santos MA, Marques SM, Niclos-Gutierrez J, Gonzalez-Perez MJ, Dominguez-Martin A, Choquesillo-Lazarte D, Szewczuk Z, Mansoori D, Toso L (2014) A new bis-3-hydroxy-4-pyrone as a potential therapeutic iron chelating agent. Effect of connecting and side chains on the complex structures and metal ion selectivity. J Inorg Biochem 141:132-143

Poreba M, Kasperkiewicz P, Snipas S, Fasci D, Salvesen G, Drag M (2014) Unnatural amino acids increase sensitivity and provide for the design of highly selective caspase substrates. Cell Death Differ 21(9):1482-1492

Szewczuk Z, Siemion IZ, Wieczorek Z (1996) Immunological properties of the thymopentin-like fragments of HLA-DQ. Mol Immunol 33(11):903-908

Tawata S (1994) Purification method of mimosine for leaves and stems of Leucaena leucocephala de Wit. Agric Chem 41:18-22 (in Japanese)

Toso L, Crisponi G, Nurchi VM, Crespo-Alonso M, Lachowicz JI, Santos MA, Marques SM, Niclós-Gutiérrez J, González-Pérez JM, Domínguez-Martín A, Choquesillo-Lazarte D, Szewczuk Z (2013) A family of hydroxypyrone ligands designed and synthesized as iron chelators. J Inorg Biochem 127(0):220-231

Toso L, Crisponi G, Nurchi VM, Crespo-Alonso M, Lachowicz JI, Mansoori D, Arca M, Santos MA, Marques SM, Gano L, NiclósGutíerrez J, González-Pérez JM, Domínguez-Martín A, Choquesillo-Lazarte D, Szewczuk Z (2014) Searching for new aluminium chelating agents: a family of hydroxypyrone ligands. J Inorg Biochem 130(0):112-121

Upadhyay A, Chompoo J, Taira N, Fukuta M, Gima S, Tawata S (2011) Solid-phase synthesis of mimosine tetrapeptides and their inhibitory activities on neuraminidase and tyrosinase. J Agric Food Chem 59(24):12858-12863

Xuan T, Elzaawely A, Deba F, Fukuta M, Tawata S (2006) Mimosine in Leucaena as a potent bio-herbicide. Agron Sustain Dev 26(2):89

Publisher's Note Springer Nature remains neutral with regard to jurisdictional claims in published maps and institutional affiliations. 